\title{
Relato de ocorrência da ferrugem da teca, causada por Olivea neotectonae no Estado de Goiás
}

\section{Report of teak rust, caused by Olivea neotectonae in the Goiás State}

\author{
Mônica Lau da Silva Marques ${ }^{1}$, Jéssica Maria Israel Jesus ${ }^{2}$, Marcos Claudio da Silva Virtuoso ${ }^{3}$, Valter Santos Marques ${ }^{4}$, Gil \\ Rodrigues Santos 5
}

Resumo: A Teca (Tectona grandis L.) é uma planta originaria da Ásia e vêm sendo cultivada principalmente nas regiões Norte e Centro Oeste do Brasil. Porém algumas doenças podem provocar danos à produtividade e crescimento desta espécie, dentre estas fitopatologias está à ferrugem. Assim objetivou-se a relatar a ocorrência do fungo Olivea neotectonae, causador da ferrugem na teca no Estado de Goiás. Em maio de 2013, foram observadas folhas da teca com sintomas de necroses que posteriormente provocavam desfolha precoce das plantas. Para avaliação inicial, folhas de teca foram coletadas em plantas localizadas na área do Instituto Federal Goiano Câmpus Ceres-GO. Em seguida, estas foram levadas ao laboratório de Microbiologia do Departamento de Ciências Agrárias. Na observação em microscópio óptico, foram visualizadas e medidas as estruturas fúngicas. Diante dos resultados obtidos no presente trabalho, pode-se concluir que o fungo causador de necroses em plantas observadas no estado de Goiás, trata-se do patógeno Olivea neotectonae, agente causal da ferrugem da Teca.

Palavras-chaves: Tectona grandis L.; fitopatologia; danos econômicos; Silvicultura.

Abstract: Teak (Tectona grandis L.) is an Asian plant and it has been cultivated mainly in the North and Midwest of Brazil. However, some diseases can decrease its productivity and growth, such as rust (Olivea neotectonae). This study aimed at reporting $O$. neotectonae in teak for the first time in the Goiás State. In May 2013, teak leaves were found with necrosis and subsequently fell untimely causing defoliation in plants. As initial analysis, teak leaves were collected from plants located in the area of the Federal Institute Goiano Campus Ceres-GO. Then leaves were taken to the microbiology laboratory of the Department of Agricultural Sciences and analyzed as well as measured under optical microscope for fungal structures. Based on the results of this study, we conclude that the causative fungus necrosis found in plants in the Goiás State is Olivea neotectonae, the causal agent of rust teak.

Key words: Tectona grandis L; plant pathology ; economic damage ; Forestry.

\footnotetext{
*Autor para correspondência

Recebido para publicação em 26/09/2015; aprovado em 23/12/2015

${ }^{1}$ Eng. Agrônoma Mestre em Fitopatologia, Professora Instituto Federal Goiano - Câmpus Ceres, Ceres - Goiás; mlnemalau@ gmail.com.

${ }^{2}$ Estudante de Agronomia, Instituto Federal Goiano - Câmpus Ceres, Ceres - Goiás; E-mails: jessicamaryisrael@ hotmail.com ; marcosc007@hotmail.com

${ }^{3}$ Eng. Agrônomo Doutor em Solos, Professor Instituto Federal Goiano - Câmpus Ceres, Ceres - Goiás; mltopografiavalter@gmail.com

${ }^{4}$ Eng. Agrônomo doutor em Fitopatologia, Professor Universidade Federal do Tocantins, Campus Universitário de Gurupi-Tocantins; gilrsan@ uft.edu.br
} 


\section{INTRODUÇÃO}

A espécie Teca (Tectona grandis L.), pertence a família das Verbanaceae, é uma espécie exótica, originária da Índia e Indonésia (LORENZI, et al., 2003), cultivada para produção de madeira para serraria (FIGUEIREDO, 2001). Devido a sua resistência, durabilidade, baixo peso e qualidades estéticas da madeira, esta espécie tem sido muito valorizada e atualmente está sendo muita empregada na fabricação de moveis finos e na construção naval (FIGUEIREDO et al., 2005; TONINI et al., 2009), o que tem despertado o seu cultivo principalmente nas regiões Norte e Centro Oeste do Brasil.

No Brasil, os plantios comerciais iniciaram no final da década de 1960, em Cáceres, Estado de Mato Grosso, ocupando nesse estado 60 mil hectares de um total estimado de 100 mil ha plantados (SANTOS et al., 2010). A teca apresenta características de durabilidade, estabilidade, resistência natural ao fogo e densidade média de $0,65 \mathrm{~g} / \mathrm{cm}^{3}$ (GOH; GALIANA, 2000). De acordo com Borges (2014), essas características incentivaram a demanda no mercado internacional, merecendo com isto fortes estímulos aos investimentos em reflorestamentos de teca no Brasil.

A cultura encontra-se consolidada no Brasil, entretanto, a rápida expansão para diferentes regiões de cultivo e o manejo inadequado têm favorecido a ocorrência de vários problemas de origem biótica e abiótica, provocando danos significativos (SANTOS et al., 2010). Dentre os fungos que podem provocar danos à produtividade e crescimento desta planta está à ferrugem, causada pelo fungo Olivea neotectonae que pertence à Ordem Uredinales.

A presença do patógeno causador da ferrugem em Teca aparece tanto em mudas como em plantas adultas de várias idades, sendo que os sintomas, que se iniciam na superfície adaxial da folha, começam com pequenas manchas necróticas que coalescem e podem englobar toda a superfície foliar, levando a folha a apresentar um aspecto de queima, com congruente desfolha da planta. Já na superfície abaxial equivalente a área necrosada pode se observar urédias pulverulentas de coloração amarelo laranja onde se observa a intensa formação de uredosporos (BONALDO et al., 2011).

De acordo com Pieri et al., (2011), o patógeno foi descoberto pela primeira vez na Ásia e até recentemente estava limitada apenas à essa região, mais com o tempo foram descobertos focos dessa doença em vários outros países. No continente americano, em novembro de 2003, ocorreu o primeiro relato no Panamá, seguido por Costa Rica em janeiro de 2004 (ARGUEDAS, 2004), setembro no Equador (BELEZACA, 2004) e em dezembro foi detectado no México (NAPPO, 2004). No ano de 2005 foi registrado na Colômbia (CÉSPEDES e YEPES, 2007) e em Cuba no mês de novembro de 2006 (PÉREZ et al., 2008). Na Austrália, foi relatado em junho de 2006 (DALY et al., 2006). No Brasil, em maio de 2009, folhas de Teca provenientes de Pontes, Lacerda e Cáceres no Estado do Mato Grosso, Imperatriz no Maranhão, São Miguel do Tocantins no Tocantins e de Botucatu no Estado de São Paulo, foram constatadas a presença desse patógeno (PIERI et al., 2011).

Diante disso, objetivou-se relatar a ocorrência da ferrugem da teca no Estado de Goiás.

\section{MATERIAL E MÉTODOS}

Em maio de 2013, foram observadas folhas de teca (Tectona grandis L.) com sintomas de necroses que posteriormente provocavam desfolha precoce das árvores (Figuras 1A.; 1B.). Para avaliação inicial, folhas de teca com esses sintomas, foram coletadas em plantas localizadas na área do Instituto Federal Goiano Câmpus Ceres-GO, município de Ceres, Goiás, localizada na latitude $\mathrm{S} 15^{\circ} 21^{\prime}$ 00', longitude W 49 35' 57', e altitude de $564 \mathrm{~m}$. O clima regional segundo a classificação de köeppen é do tipo Aw. Posteriormente, estas foram levadas ao laboratório de Microbiologia do Departamento de Ciências Agrárias. Inicialmente, as lesões foram observadas e raspadas sob Lupa estereoscópica binocular e em seguida preparou-se as lâminas para analise em microscópio óptico, onde visualizou-se e mediu-se as estruturas fúngicas.

\section{RESULTADOS E DISCUSSÃO}

Em observação na lupa estereoscópica binocular, visualizou-se pústulas (uredinias) na face inferior. As pústulas eram subepidermais, erumpentes de coloração laranja com uredosporos (Figuras 2A. ; 2B).

A partir da visualização em microscópio óptico foi possível observar e aferir as seguintes estruturas fúngicas: uredínios hipófilos, 0,2-0,5 $\mathrm{mm}$ de diâmetro, de cor amarelada e aspecto pulverulento, gregários, subepidermais, irrompentes, paráfises densas e marginais; paráfises cilíndricas, encurvadas, 27-55 x 7-13 $\mu \mathrm{m}$, unidas na base, lisas, paredes engrossadas distalmente, hialinas a marrom pálida (Figura 3); Urediniósporos pedicelados, subglobosos, obovóides a elipsóides, 21-24 (-30) x 16-18 (-20) $\mu \mathrm{m}$, quando novos com conteúdo amarelo-alaranjado, parede de coloração marrom-canela, equinulada, medindo $0,5-1,0 \mathrm{~mm}$ de espessura, poros germinativos inconspícuos (Figuras 3A.; 3B.).

O formato e tamanho dos fungos encontrados se assemelham aos descritos por Ferrari (2009), ao relatar o aparecimento do fungo em Mato Grosso, com forma urédios hipófilos, pulverulentos, subepidermais, paráfises cilíndricas, curvas e proeminente no ápice. Os urediniosporos são unicelulares ovalados, arredondados e equinulados, hialinos a amarelados, com tamanho variando de 18-28 x 14-22 $\mu$. Características semelhantes foram descritas no trabalho de Gasparotto et al., 2013, ao descrever a ferrugem da teca no estado do Amazonas.

Segundo Bonaldo et al., (2011), por esse patógeno apresentar uredosporos ovoides, unicelulares, equinulados, com coloração amarelo-alaranjado, apresentando tamanho variando de 12,3-24,8 x 14,7-24,8 $\mu \mathrm{m}$ e ausência de teliosporos este é identificado como Olivea tectonae. Porém Pieri et al. (2011), estudando o nome específico deste fungo sugerem que o nome seja alterado, pois de acordo com estes autores, este fungo não apresenta espermogônios e nem écios conhecidos e telios não foram encontrados no Brasil, mas que há formação de teliósporos tardiamente pelos uredínios ou em soros, o que põe em dúvida o relato de Bonaldo, relatando que não há presença de teliosporos. Desta forma, mantém-se o nome específico para Olivea neotectonae. 
Figura 1. Árvores de Teca com sintomas de ferrugem em suas folha.
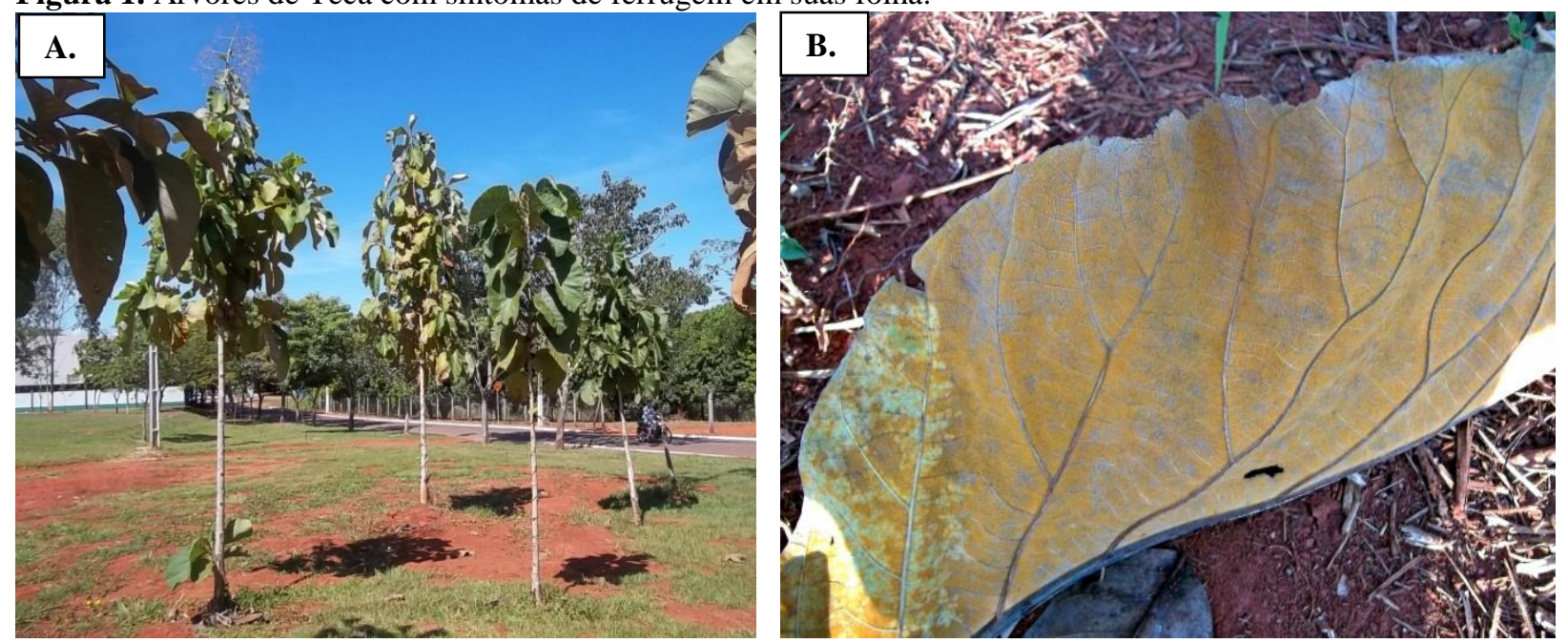

Figura 2: Lesões das folhas observadas na Lupa estereoscópica binocular.
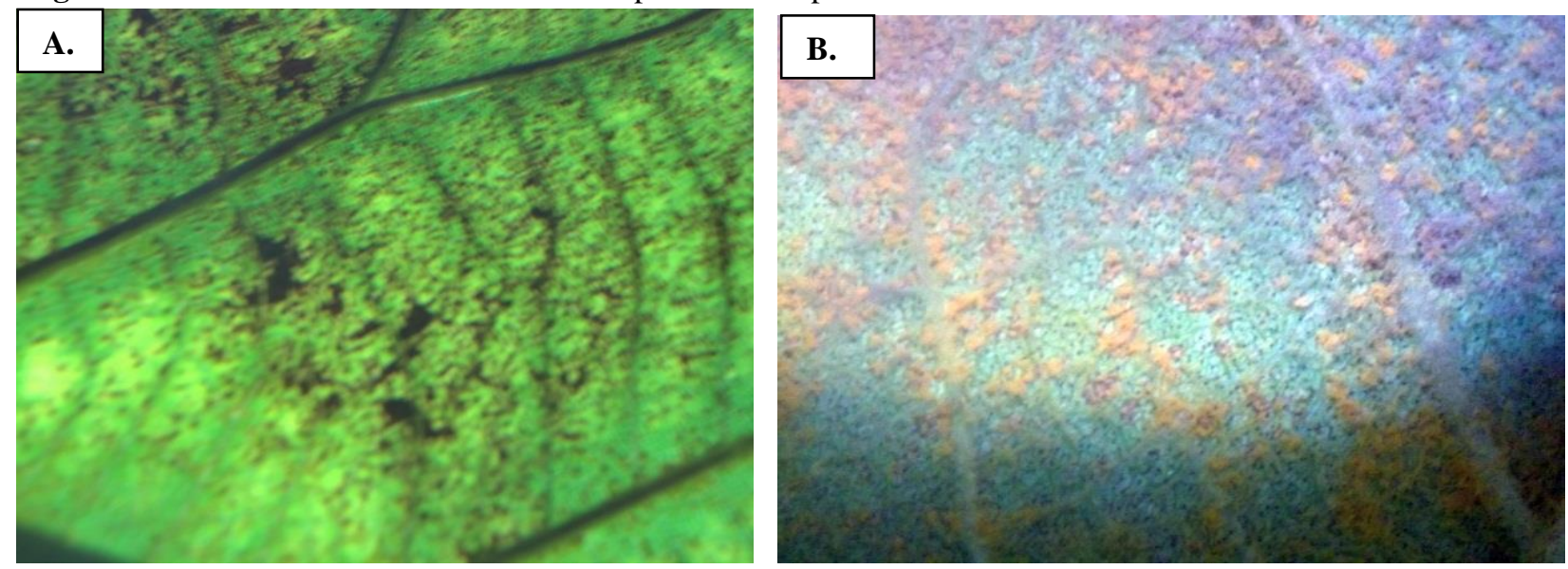

Figura 3: Estruturas fúngicas visualizadas sob microscópio óptico Olympus cx31

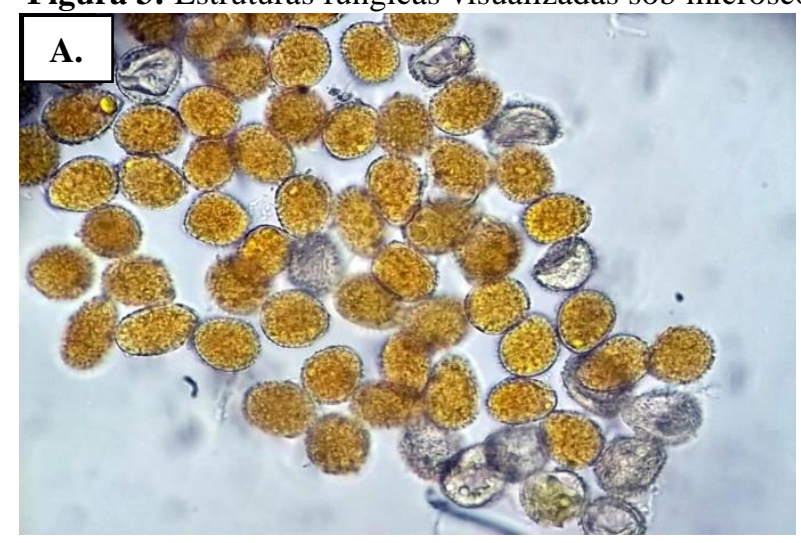

Na literatura analisada verificou-se que há escassez de informações sobre a quantificação de danos provocados por esta doença, porém Sharma et al. (1985) e Arguedas (2004), relatam que os maiores danos são mais frequentes da fase de crescimento de plântulas até plantas com 10 anos, devido ao surgimento de necroses e à desfolha precoce. Gasparotto; Pereira (2013) descreveram que os primeiros sintomas ocorrem na segunda folha com o limbo expandido, através de reduzidos flecks, que progridem profusamente na terceira folha, formando pequenas manchas cloróticas ligeiramente esbranquiçadas, dispostas nos espaços internervurais. Posteriormente, as áreas cloróticas tornam-se marrom-claras,

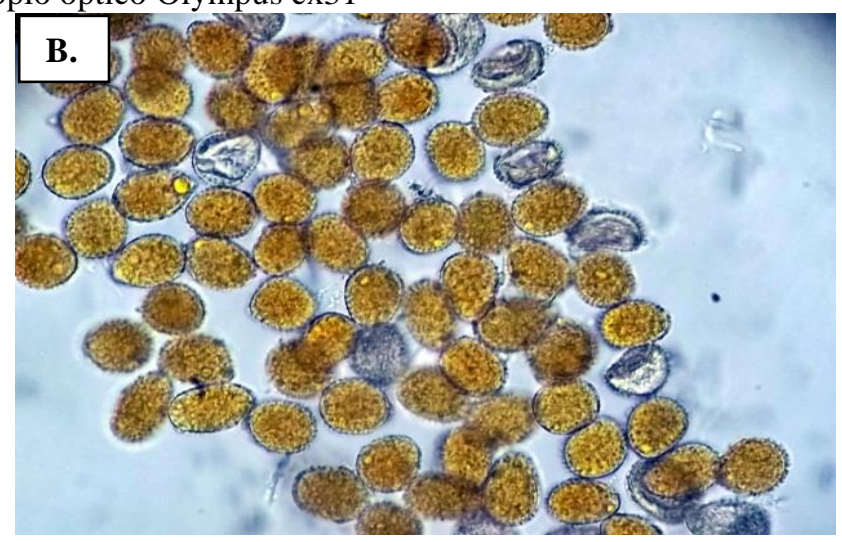

e na face abaxial das folhas formam-se muitas pústulas esporuladas de coloração amarela, sobre fundo marrom escuro. As pústulas coalescem, necrosam o limbo foliar de forma generalizada, causando a desfolha das plantas.

De acordo com Ferrari (2011), nas plantas adultas os sintomas são mais drásticos nas folhas mais velhas. As manchas cloróticas podem evoluir para necróticas até queima generalizada. Nas plântulas, a doença manifesta-se nos cotilédones sob a forma de pequenos pontos cloróticos, onde se observam, na face inferior da folha, pústulas contendo urediniosporos. Em plantas jovens com menos de 2 metros de altura, os sintomas prevalecem nas folhas mais baixas. 
De acordo com Gasparotto; Pereira (2013) os esporos, transportados pelos ventos, são os principais propágulos de dispersão do patógeno. A disseminação dos esporos é favorecida pelo vento nos períodos secos e requer precipitação para o seu estabelecimento (FERRARI, 2011). O fungo penetra através da superfície inferior do limbo foliar, que em curto período de tempo é recoberta por esporos alaranjados (GASPAROTTO; PEREIRA 2013).

A escolha de uma área com condições adequadas de solo e clima é o primeiro passo para diminuir os riscos dos fatores que podem afetar o desenvolvimento florestal, dentre estes as doenças (CALDEIRA et al., 2013).

O controle desta patologia é dificultado por vários fatores, dentre eles, pela capacidade de disseminação do fungo e da facilidade de dispersão dos esporos através do vento, e ao fato que as árvores atingirem grande porte.

Existem poucos estudos em relação ao controle dessa doença. Como medida de exclusão, recomendam-se a interceptação do material doente, a eliminação do patógeno de material propagativo, o plantio de mudas sadias livres do fungo, o isolamento mediante quarentena e a proibição do trânsito de plantas (CALDEIRA et al., 2013). Medidas de evasão ou escape são ineficientes no controle dessa patologia (GASPAROTTO; PEREIRA, 2013).

Não existem fungicidas registrados no País para o controle dessa doença. Plantas estressadas devido aos trabalhos de poda e raleamento podem ser mais suscetíveis (FERRARI, 2011). De acordo com Gasparotto; Pereira (2013), os métodos de controle direto da ferrugem não são recomendados, devido à doença se manifestar de forma generalizada nos povoamentos, e a ocorrência se darem em folhas senescentes e em povoamentos sob estresse. Em razão disso, o manejo silvicultural adequado é muito importante, principalmente nas operações de desrama e desbaste (ARGUEDAS, 2004). Adotar o manejo adequado que inclua essas práticas em plantas jovens é indicada, pois melhora a ventilação na plantação (GASPAROTTO; PEREIRA, 2013).

\section{CONCLUSÕES}

Diante dos resultados obtidos conclui-se que o fungo causador de necroses em plantas observadas no estado de Goiás, trata-se do patógeno Olivea neotectonae, agente causal da ferrugem da Teca.

\section{REFERÊNCIAS BIBLIOGRÁFICAS}

ARGUEDAS, M. La roya de la teca Olivea tectonae (Rac.): consideraciones sobre su presencia en Panamá y Costa Rica. Kurú: Revista Forestal, Costa Rica, v. 1, n.1, p.1-16, 2004.

BELEZACA, C. La roya de la teca (Tectona grandis L.f.) presente en la zona central del litoral ecuatoriano, 2004. Disponível em: [http.www.uteq.edu.ec/produccion/madera/ general.htm], Acesso em: 26 jul. 2015.

BONALDO, S. M.; BARCELI, A. C.; TRENTO R. A.; GASPAROTTO, F.; TAFFAREL C. Relato oficial da ocorrência de Olivea tectonea em teca (Tectona grandis) no Brasil. Summa Phytopathol, Botucatu, v. 37, n. 3, p. 153, 2011.
BORGES, R. C. F. Etiologia do cancro da teca e caracterização patogênica e molecular de Lasiodiplodia theobromae. Brasília: UNB, 2014, 86 p.

CALDEIRA, S. F.; SANTOS, A. F.; AUER, C. G. Doenças da teca. In: GASPAROTTO, L.; BENTES, J. L. S.; PEREIRA, J. C. R. Doenças de espécies florestais arbóreas nativas e exóticas na Amazônia. Brasília, DF: Embrapa, 2013.

CÉSPEDES, P. B.; YEPES, M. S. Nuevos registros de royas (Uredinales) potencialmente importantes en Colombia. Revista Facultad Nacional de Agronomia de Medellín, Medellín, v.60, n.1, p.3645-3655, 2007.

DALY, A. M.; SHIVAS, R. G.; PEGG, G. S.; MACKIE, A. E. First record of teak leaf rust (Olivea tectonae) in Australia. Australasian Plant Disease Notes, Australia v.1, p.25-26, 2006.

FERRARI, J. T. Ocorrência de ferrugem (Olivea tectonae) em plantas de Teca no Brasil. In: 22 ${ }^{\mathrm{a}}$ Reunião Anual do Instituto Biológico, 2009, São Paulo. O Biológico, 2009. v. 71. p. 165.

FERRARI, J. T. Ferrugem (Olivea tectonae) em plantas de teca. São Paulo: Instituto Biológico, p. 6, 2011. (Documento Técnico, 009).

FIGUEIREDO, E. O.; OLIVEIRA, A. D.; SCOLFORO J. R. S. Análise econômica de povoamentos não desbastados de Tectona grandis $f$., na microrregião do baixo rio acre. Cerne, Lavras, v. 11, n. 4, p. 342-353, out./dez. 2005.

FIGUEIREDO, E.O. Reflorestamento com teca (Tectona grandis) no estado do Acre. Embrapa, Rio Branco, p.28, 2001.

GASPAROTTO, L.; PEREIRA, J. C. R.; REZENDE, D. V. A ferrugem da teca no Amazonas. Tropical Plant Pathology, Viçosa, v. 38, 2013. (CD ROM)

GASPAROTTO, L.; PEREIRA, J.C. R. A Ferrugem da Teca no Estado do Amazonas. Embrapa Amazônia Ocidental, Manaus, p.4, 2013. (Comunicado Técnico 101).

GOH, D. K. S.; GALIANA, A. Vegetative propagation of teak. JIRCAS working Report, Tuskuba, n.16, p. 35-43, 2000.

LORENZI, H. Árvores Exóticas no Brasil: madeireiras, ornamentais e aromáticas. Nova Odessa: Instituto Plantarum, 2003. 384 p.

NAPPO Pest Alert - Official Pest Reports for Mexico. Detección de la Roya de la Teca (Olivea tectonae), (Rac.) Thirum. Chaconiaceae, en el municipio de Las Choapas, Veracruz, México, 2005. Disponível em: http://www.pestalert.org/espanol/oprDetail.cfm?oprID=142\& keyword=Olivea\%20tectonae. Acesso em 21 de agosto de 2015 .

PÉREZ, M.; LÓPEZ, M.O.; MARTÍ, O. Olivea tectonae, leaf rust of teak, occurs in Cuba. New Diseases Reporter, Cuba, v.17, p.32, 2008. 
PIERI, C.; PASSADOR, M. M.; FURTADO, E.L.; CARVALHO JUNIOR, A. A. Novas observações sobre a ocorrência da ferrugem da teca (Tectona grandis) no Brasil e revisão taxonômica do patógeno. Summa Phytopathol, Botucatu, v. 37, n.4, p.199-201, 2011.

SANTOS, A. F.; AUER, C. G.; CALDEIRA, S. F. Impactos potenciais de doenças em espécies florestais emergentes no Brasil. Tropical Plant Pathology, Lavras, v. 35, p. 83-85, 2010 .

SHARMA, J. K.; MOHANAN, C.; FLORENCE, E. J. M. Disease survey in nurseries and plantations of forest tree species grown in Kerala. Kerala Forest Research, India, v. 36, p. $275,1985$.

TONINI, H.; COSTA, M. C. G.; SCHWENGBER, L. A. M. Crescimento da Teca (Tectona grandis) em reflorestamento na Amazônia Setentrional. Pesquisa Florestal Brasileira, Colombo, n. 59, p. 05-14, 2009. 